\title{
AS “AREIAS DE VÁRZEA DO LÍRIO” E O NEOLÍTICO DA SERRA DA BOA VIAGEM (FIGUEIRA DA FOZ, PORTUGAL): INFLUÊNCIA DA ENVOLVENTE GEOLÓGICA DO MEIO NATURAL NA NEOLITIZAÇÃO DO TERRITÓRIO
}

\author{
Pedro Miguel Callapez ${ }^{(1)} \&$ Miguel de Carvalho(2) $^{(2)}$
}

\section{Resumo}

Abstract

\begin{abstract}
O longo flanco meridional do maciço calcário da Serra da Boa Viagem assenta, sobretudo, em unidades espessas, greso-conglomeráticas e pelíticas avermelhadas, do Jurássico superior e Cretácico inferior. Neste contexto e no espaço da bacia de drenagem do Rio de Carritos, o principal dos sistemas dendríticos locais orientados para o estuário do Rio Mondego, é reconhecido sob a designação de Areias de Várzea do Lírio um conjunto de depósitos de areias finas, maturas, com características eólicas, as quais preenchem parte das linhas de cumeada e se encontram em trânsito ao longo das vertentes dos vales contíguos, selando depressões locais da paleotopografia pós-Würm. Durante o levantamento cartográfico de campo desta unidade arenosa, foi reconhecida a sua relação directa com a ocupação da região durante o Neolítico, sobretudo a sua fase mais antiga, cardial. Desta forma, foi possivel proceder à reavaliação detalhada dos arqueossítios existentes entre a Várzea do Lírio, Asseiceira, Cubelo, Vale da Junqueira e Arruelas, tendo sido reconhecidos vários locais de ocupação, para além de materiais líticos e cerâmicos dispersos com idades e tipologias que variam entre o Neolítico Antigo e o Calcolítico Final. Na sua maioria, estes locais correspondem aos descritos originalmente pelo arqueólogo figueirense Santos Rocha, ficando confirmada a sua localização precisa e extensão. A sua existência sugere um povoamento significativo da região durante o Neolítico, consentâneo com o óptimo climático do Holocénico Médio. Durante este intervalo existiriam condições ambientais particularmente favoráveis nos vales férteis com solos arenosos da bacia do Rio de Carritos, em conexão com o meio estuarino da margem norte do Mondego.
\end{abstract}

Palavras-chave: Pré-História Recente; Neolítico Antigo; estações de superfície; depósitos arenosos; Serra da Boa Viagem.

\begin{abstract}
The "Areias de Várzea do Lírio" (Varzea do Lirio Sands) and the Neolithic of Serra da Boa Viagem (Figueira da Foz, Portugal): influence of the geologic background of the natural environment on the neolithization of territory.

The large southern hillslope of the calcareous massif of Serra da Boa Viagem (Figueira da Foz, West coast of Portugal) mainly lies on Upper Jurassic and Lower Cretaceous thick units of sandy-conglomerates and reddish pelites. On this context and inside the area occupied by the Carritos River drainage basin, the main local dendritic system oriented to the Mondego River estuary, we designate as Várzea do Lírio Sands (Areias de Várzea do Lírio) a set of deposits with mature fine sands resulting from aeolian processes. These deposits are mainly found on the summit lines and slopes of the contiguous valleys, where they infill local depressions of the post-Würmian palaeotopography. During the field geologic mapping of this sandy unit, an obvious connection with the Neolithic settlement of the region was recognized, especially when the ancient Neolithic Cardial is concerned. By this way, it was possible to reevaluate in detail the archaeosites found between the localities of Várzea do Lírio, Asseiceira, Cubelo, Junqueira valley and Arruelas, allowing the recognition of several settlement places and scattered lithic and ceramic materials with ages and typologies that range from the ancient Neolithic to the Late Calcolithic. Mostly, these places are the same that had been described during the late XIX's by the Portuguese archaeologist Santos Rocha, being confirmed their precise location and extension. Their existence suggests a significant Neolithic settlement in the region during the Middle Holocene climatic optimum, when more favorable environmental conditions were generated in the fertile valleys with sandy soils of the Carritos River basin, near the northern margin of the Mondego estuary.
\end{abstract}

Key-words: Recent Pre-history; Ancient Neolithic; surface sites; sand deposits; Serra da Boa Viagem; Portugal.

(1) Departamento de Ciências da Terra e Centro de Geofísica da Universidade de Coimbra. Largo Marquês de Pombal, 3001-401 Coimbra, Portugal.callapez@dct.uc.pt

(2) Mestre em Geologia (Estratigrafia do Quaternário). Rua Adro de Baixo, 6, Coimbra, Portugal. miguel-carvalho@livro-antigo.com 


\section{INTRODUÇÃO E HISTÓRICO DE PESQUISAS}

A Serra da Boa Viagem tem vindo a ser reconhecida, desde os primórdios dos estudos científicos de Arqueologia em Portugal, como uma das áreas relevantes para o estudo da neolitização do território (Fig. 1). As primeiras descobertas e muitos dos trabalhos até hoje publicados sobre os sítios arqueológicos da Pré-História Recente nela existentes devem-se, sobretudo, à actividade pioneira de António dos Santos Rocha, decorrida entre o último quartel de novecentos e o seu óbito, ainda precoce, em 1910 (para uma leitura biográfica e bibliográfica mais exaustivas, consulte-se H. Vilhena 1937).

As respectivas colecções que nos legou, conservam-se e merecem grande destaque nos acervos do Museu Municipal Dr. Santos Rocha, na Figueira da Foz (PEREIRA 1985, 1999), sendo indiscutível a sua importância para o histórial da própria Arqueologia em Portugal. Destas antigas colecções, importa-nos relevar os numerosos materiais líticos e cerâmicos do Neolítico Antigo, provenientes das estações humanas de Várzea do Lírio e da Junqueira, entre outras, assim como dos espólios de diversos monumentos megalíticos, ligados ao Neolítico e Calcolítico. As pesquisas efectuadas ao tempo de Santos Rocha e da Sociedade Arqueológica da Figueira da Foz (FERREIRA 1999) prolongaram-se por mais de duas décadas e incidiram, em particular, sobre a cumeada e o flanco meridional da Serra da Boa Viagem e, na sua con- tinuidade, da Serra das Alhadas, por força de uma maior concentração de achados nessas áreas (RocHA 1905, 1940, 1954, 1971, 1975). Como testemunho maior desta época da Pré-História Recente, ainda hoje conservado no seu primitivo local de edificação, destaca-se o dólmen das Carniçosas (PEREIRA 1975) (Fig. 2), cujos esteios de arenito vermelho foram talhados, em parte, a partir de estratos do Jurássico Superior local, ainda hoje aflorantes nas vertentes do Vale da Junqueira e Vale Romão.

Mais tardiamente e na sequência de um maior incremento dos estudos de Pré-História Recente a partir dos anos 60 do século passado, a temática do Neolítico figueirense foi retomada, entre outros, por V. Guerra (1969), V. Guerra \& O.V. Ferreira (1968-70, 1972, 1979), J. Guilaine \& O.V. Ferreira (1970), S. Oliveira Jorge (1979) e R. Vilaça (1988). Neste âmbito, foram objecto de análise mais atenta os materiais cerâmicos decorados e de pedra polida provenientes das estações figueirenses, assim como os monumentos megalíticos descritos por Santos Rocha, inventariados quanto à sua localização, espólio e estado de conservação presente.

Numa perspectiva mais recente há ainda que considerar as abordagens de J. Perpétuo \& P.S. Carvalho (2006) e A.F. Carvalho (2008), das quais a primeira respeita a intervenção arqueológica no dólmen das Carniçosas e, a segunda, a uma síntese do estado da arte sobre o Neolítico Antigo da região do Baixo Mondego.

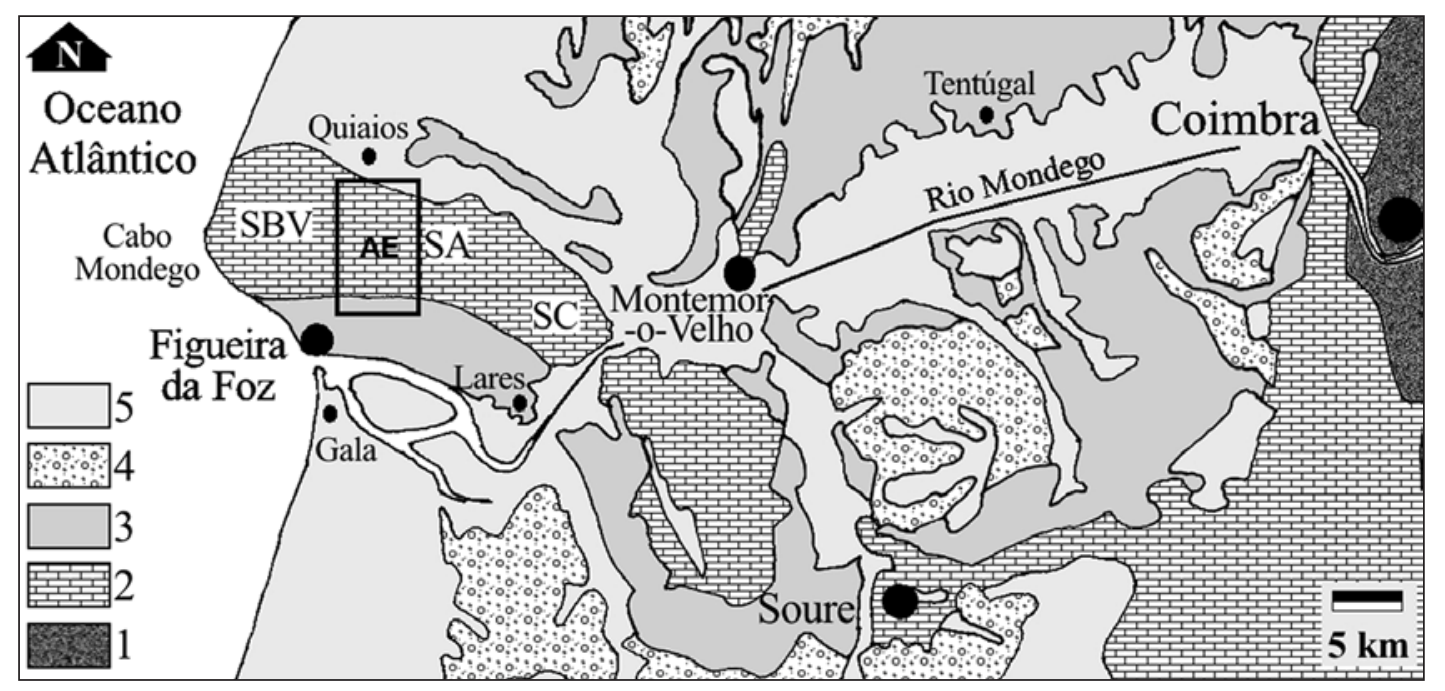

Fig. 1. Esboço geológico da Região do Baixo Mondego, incluindo o maciço calcário da Serra da Boa Viagem e a localização aproximada da área estudada (rectângulo AE). Principais relevos: SBV - Serra da Boa Viagem; SA - Serra das Alhadas; SC - Serra de Castros; 1 - Soco Pré-Câmbrico; 2 - Jurássico; 3 - Cretácico; 4 - Paleogénico, Miocénico e Pliocénico; 5 - Quaternário.

Fig. 1. Simplified geologic map of Baixo Mondego Region, including the calcareous massif of Serra da Boa Viagem and the approximate location of the studied area (AE rectangle). Main relieves: SBV - Serra da Boa Viagem; SA - Serra das Alhadas; SC - Serra de Castros; 1 - Precambrian basement; 2 - Jurassic; 3 - Cretaceous; 4 - Palaeogene, Miocene and Pliocene; 5 - Quaternary. 


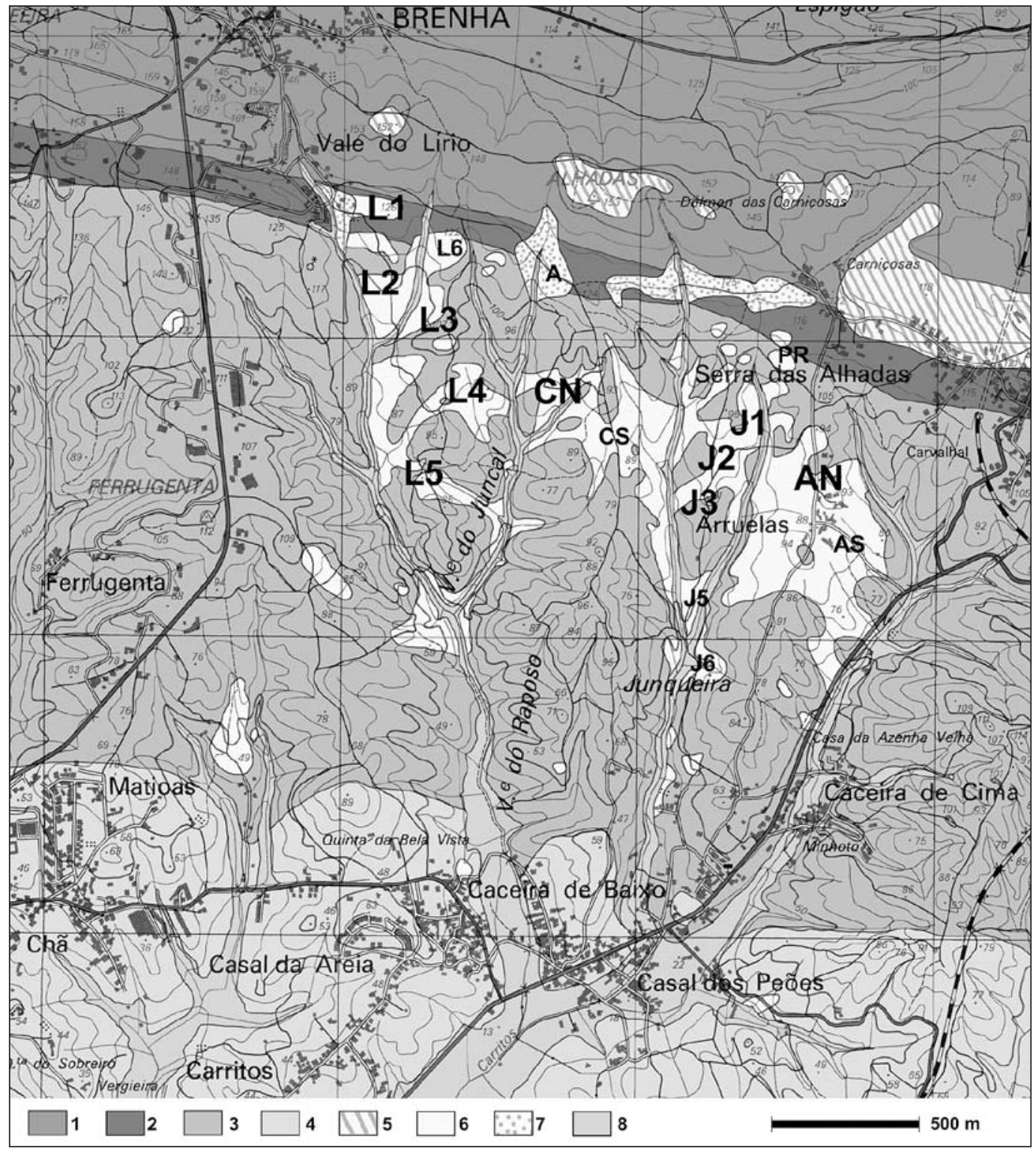

Fig. 2. Carta geoarqueológica da bacia de drenagem do Rio de Carritos, no flanco meridional do maciço calcário da Serra da Boa Viagem e Serra das Alhadas. Observam-se em primeiro plano a rede de drenagem com padrão dendrítico, as manchas de depósitos arenosos e a posição dos locais de ocupação. 1 - Unidades margo-calcárias do Toarciano e Jurássico Médio; 2 - Unidades carbonatadas do Oxfordiano; 3 - Formação dos Arenitos de Boa Viagem (Quimeridgiano a Titoniano); 4 - Formação da Figueira da Foz (Cretácico Inferior); 5 - Depósito culminante da serra (possível equivalência ao Depósito da Bandeira); 6 - Areias de Várzea do Lírio; 7 - Depósitos coluvionares em trânsito; 8 - Aluviões e coluviões de fundo de vale. Principais arqueossítios da Pré-História Recente: L1 - Lírio 1; L2 - Lírio 2; L3 - Lírio 3; L4 - Lírio 4; L5 - Lírio 5; CN - Cubelo Norte; J1 - Junqueira 1; J2 - Junqueira 2; J3 - Junqueira 3; AN - Arruelas Norte. Outros sítios: L6 - Lírio 6; A - Asseiceira; CS - Cubelo Sul; PR - Prazo; J5 - Junqueira 5; J6 - Junqueira 6; AS - Arruelas Sul. Fundo topográfico adaptado da Carta Militar de Portugal à escala 1:25.000, folha n. ${ }^{\circ} 231$ - Figueira da Foz.

Fig. 2. Geoarchaeological map from the Rio de Carritos drainage basin, on the southern hillslope of the calcareous massif of Serra da Boa Viagem and Serra das Alhadas. In foreground can be seen the drainage system with dendritic pattern, the sand deposits, and the locations of the occupation areas. 1 - Toarcian and Middle Jurassic marly and limestone units; 2 - Oxfordian carbonate units; 3 - Arenitos de Boa Viagem Fm. (Kimmeridgian and Tithonian); 4 - Figueira da Foz Fm. (Lower Cretaceous); 5 - Uppermost deposits of the calcareous massif (probably equivalent to the Bandeira deposit); 6 - "Areias de Várzea do Lírio" unit (Várzea do Lírio sands); 7 - Colluvial deposits in transit; 8 - Alluvial and colluvial deposits of valley bottom. Main arqueosites from Recent Prehistory: L1 - Lírio 1; L2 - Lírio 2; L3 - Lírio 3; L4 - Lírio 4; L5 - Lírio 5; CN - Cubelo Norte; J1 - Junqueira 1; J2 - Junqueira 2; J3 - Junqueira 3; AN - Arruelas Norte. Other sites: L6 - Lírio 6; A - Asseiceira; CS - Cubelo Sul; PR - Prazo; J5 - Junqueira 5; J6 - Junqueira 6; AS - Arruelas Sul. Bottom topography adapted from the Carta Militar de Portugal, scale 1:25.000, map n. ${ }^{\circ} 231$ - Figueira da Foz 
Infelizmente, dada a proximidade de alguns dos principais eixos viários regionais, assim como a crescente antropização do espaço da Serra da Boa Viagem, a área de maior interesse arqueológico tem vindo a ser sujeita a crescentes intervenções danosas, as quais acabam por resultar em destruições, ou mesmo, no desaparecimento de contextos arqueológicos de importância significativa. Ainda recentemente, após finalização do troço da auto-estrada A17 que atravessou o Vale de Junqueira e resultou na destruição, ainda que parcial, dos arqueossítios do Prazo e de Arruelas, o principal local de ocupação neolítico deste mesmo vale foi recoberto por espesso depósito de aterro, ficando dificultada qualquer intervenção arqueológica futura.

Desta forma, num momento em que a valorização do património cultural dos municípios assume relevância crescente, o presente texto pretende contribuir para uma futura carta arqueológica figueirense, relevando sítios e estações de superfície do flanco meridional da Serra da Boa Viagem e Serra das Alhadas, tendo em conta a sua extensão, diversidade de materiais, importância histórica e grau de risco presente.

Neste sentido e dentro de actividades de investigação em curso, foram efectuados trabalhos de campo espaçados por vários anos e períodos sazonais, no sentido de aproveitar desmatamentos e a própria evolução do coberto vegetal. Como metodologia de análise, optou-se pela localização e reinventariação das estações de superfície descritas por Santos Rocha, em simultâneo com a pesquisa de novos locais de interesse arqueológico ainda inéditos, utilizando-se para tal o GPS e um fundo topográfico adaptado à escala 1/10.000. Infelizmente, as descrições originais foram acompanhadas por localizações pouco precisas ou incertas, à luz de bases cartográficas modernas. Este facto, associado às modificações na paisagem ocorridas nos últimos 130 anos e ao abandono a que alguns dos locais foram votados, contribuiu bastante para dificultar a sua redescoberta.

Nos primeiros reconhecimentos de campo tornou-se, também, evidente a relação que existe entre a localização destes locais de ocupação pré-histórica e a cobertura, densa mas descontínua, de depósitos de areias holocénicas que colmatam parte das vertentes e linhas de água da bacia de drenagem do Rio de Carritos (Fig. 2). É, com efeito, nesta área situada sensivelmente a meia encosta do flanco sul da serra que se centram muitos dos sítios e designações toponímicas mencionadas, ao tempo, por Santos Rocha (Várzea do Lírio, Asseiceira, Cubelo, Vale Romão, Prazo, Junqueira e Arruelas, entre outros locais). O presente trabalho surge, assim, da necessidade sentida de proceder ao levantamento cartográfico e descrição desses corpos arenosos, em conjunto com a localização e reinventariação dos locais de ocupação atrás referidos, através de um esboço geológico e geoarqueológico.

\section{Contexto GeOMorfológico E GEOLÓGICO}

O maciço calcário da Serra da Boa Viagem, Serra das Alhadas e Serra de Castros constitui o principal relevo do Concelho da Figueira da Foz, individualizando-se no seio de um amplo troço, essencialmente arenoso e aplanado, da bordadura atlântica da Beira Litoral (ALMEIDA 2006). Relevo de dimensões algo modestas se comparado com as serras imponentes do Maciço Calcário Estremenho (ALMEIDA et al. 1990; CUNHA 1990), não deixa por isso de condicionar, de modo significativo, a paisagem envolvente de terras baixas, ao se entrepor entre as aluviões e braços estuarinos do Rio Mondego e a extensa planura arenosa da Gândara (CARVALHO 1964; BARBOSA et al. 1988).

A confrontação da Serra da Boa Viagem com o litoral atlântico tem lugar nas arribas calcárias do Cabo Mondego, área de tradições mineiras e reconhecida importância científica no âmbito das Ciências Geológicas e da Arqueologia (CALlapez 2008; CAllapez \& Pinto 2005, 2010; Pinto \& CAllapeZ 2006). Nesta área, através de extensos afloramentos abertos nas frentes das pedreiras, é possível observar a ossatura do maciço calcário, assente que está em formações calco-margosas do Jurássico (Sinemuriano a Oxfordiano Superior; RocHA et al. 1981) com disposição em monoclinal suavemente inclinado para Sul e condicionado por aparente actividade neotectónica (CABRAL 1995). Ao grande acidente WNW-ESSE que delimita o sopé setentrional da estrutura, deverão acrescentar-se outros degraus ou desligamentos (ALMEIDA 2006; RAMOs et al. 2009), acentuando a deformação local e variações na disposição e espessura dos depósitos, mas nem sempre susceptíveis de fácil confirmação no terreno.

No seu todo, são bastante acentuadas as diferenças observadas entre os dois flancos assimétricos da estrutura sinclinal, mais profundas entre a Bandeira e o parque eólico da Boa Viagem, mas esbatendo-se pouco a pouco no sentido da Serra de Castros. Sob este miradouro culminante as vertentes são escarpadas e, no seu sopé, abundam depósitos de vertente espessos com acumulações de blocos e termoclastos calcários, por vezes com materiais arqueológicos intercalados. Ao desenvolvimento desta longa e profunda frente de costeira não será estranha uma actuação diferencial dos processos erosivos, aproveitando o espesso corpo margoso de idade toarciana, bastante 
mais friável, que aí aflora. Estas condições favoráveis permitiram constituiram uma envolvente de grande imponência e carácter agreste, aproveitada para a edificação de diversos monumentos megalíticos.

Entre os alcantilados do Cabo Mondego e os sectores mais internos do maciço calcário, através de vários degraus morfológicos e de retalhos da actual linha de cumeada, abundam depósitos de génese e cronologia diversa, por vezes residuais e nem sempre fáceis de individualizar, mas tradutores da evolução morfogenética, e paleoclimática da região durante o Plistocénico e Holocénico (SOARES 1990; SOARES et al. 1989, 1992, 1993). Entre estes, salientam-se os depósitos associados a antigas plataformas de abrasão marinha, nomeadamente o que acompanha a cumeada da serra calcária, a partir de 210-220 m mas com possível basculamento para leste (Depósito areno-pelítico da Bandeira in A.C. Almeida, 1992, 1995) e o do denominado "Nível do Farol" (ALMEIDA op. cit.; SOARES et al. 2007), situado a 80-90 m e localmente fossilífero.

Situados a cotas quase sempre inferiores, circundando o rebordo sul da grande mancha calcária, dispõem-se outros tipos de depósitos de tendência areno-cascalhenta ou arenosa, ligados a patamares de antigos terraços fluviais, ou ainda a materiais em trânsito, provenientes da erosão do substrato jurássico e cretácico, assim como do provável desmantelamento de depósitos pré-existentes. Na realidade, para Sul da linha de afloramentos de calcários do Oxfordiano que medeia entre a entrada do Couto Mineiro do Cabo Mondego e os lugares do Lírio e de Casal das Arruelas, todo o longo flanco sul da estrutura assenta em estratos de rochas detríticas, implicando uma resposta morfológica que se traduz no encaixe de uma rede de drenagem dendrítica mais densa e dirigida para Sul ou Sudeste, assim como o desenvolvimento de pequenos degraus junto ao contacto com os calcários e ao longo das cumeadas dos vales.

Está em causa, sobretudo, a espessa Formação dos Arenitos de Boa Viagem (RochA et al. 1981), composta por alternâncias de estratos conglomeráticos e gresosos com abundantes níveis espessos de lutitos avermelhados, mas também a unidade cretácica, essencialmente greso-conglomerática que sobre ela assenta em discordância (Arenitos de Carrascal, RoCHA et al. op. cit.; equivalente a Formação de Figueira da Foz, in DiNIS 2001).

Os depósitos arenosos reconhecidos no presente estudo inserem-se neste contexto geológico particular, ao se circunscreverem à área ocupada pelos Arenitos de Boa Viagem e à bacia de drenagem do Rio de Carritos, na principal das redes com padrão dentrítico que se encaixam na fachada sul do maciço calcário (Fig. 2).

\section{As Areias de VÁrzea do Lírio}

Sob a designação de Areias de Várzea do Lírio agrupamos um conjunto muito homogéneo de depósitos arenosos, que ocupam uma área significativa dos troços superior e médio da bacia de drenagem do

Rio de Carritos. Estes depósitos definem pequenas plataformas com pendores inferiores a $10^{\circ}$ para Sul, dispostas ao longo das linhas de cumeada que separam os principais vales com orientação sensivelmente meridiana, convergentes para a Várzea dos Carritos (Fig. 2). Em simultâneo, é significativo o número de depósitos arenosos em trânsito que se observam ao longo de algumas das vertentes destes vales, formando leques de escorrência e colmatando valeiros, aqui interpretados como antigas linhas de água associadas a uma paleotopografia local pós-wurmiana e holocénica. Nos fundos côncavos de vales como os do Lírio, Juncal, Romão e Junqueira, estes corpos arenosos misturam-se com materiais aluvionares resultantes da erosão de rochas detríticas e margo-calcárias do Jurássico Médio e Superior, assim como do desmantelamento de depósitos mais antigos, situados em torno da superfície culminante do maciço calcário.

Como localidade tipo para a caracterização desta unidade foi escolhida a pequena povoação do Lírio (Fig. 2), situada cerca de $1 \mathrm{~km}$ a Sul do Alto da Brenha, em torno do ressalto morfológico que marca o contacto entre os calcários marinhos do Oxfordiano ("Calcários hidráulicos" e "Camadas marinhas ricas em lamelibrânquios"), segundo R.B. Rocha et al. (1981) e os estratos mais friáveis, greso-conglomeráticos e lutíticos de fácies deltaica, que compõem a Formação dos Arenitos de Boa Viagem. Através do caminho vicinal que se dirige para sul, a partir do fontanário local e da quinta acastelada, atravessa-se uma ampla plataforma levemente vergente em direcção à junção das duas principais linhas de água. Esta plataforma é definida por um depósito de natureza arenosa, amarelado, visível no talude do caminho ao longo de cerca de $150 \mathrm{~m}$ (Fig. 3).

A geometria do depósito mostra uma adaptação ao substrato jurássico local, o qual é composto por alternâncias de níveis com espessura decimétrica, de conglomerados e de arenitos muito grosseiros a finos, imaturos, com cimento carbonatado e/ou ferruginoso, intercalados com estratos mais espessos de lutito avermelhado. A estratificação do conjunto apresenta pendores moderados para Sul, acompanhando a estrutura geral do monoclinal subjacente ao maciço calcário. A superfície selada pelo corpo arenoso é irregular, sendo que os níveis mais grosseiros e compactos tendem a formar saliências e cornijas. Desta forma, a espessura local do depósito é bastante variável, podendo atingir valores até $3 \mathrm{~m}$. 


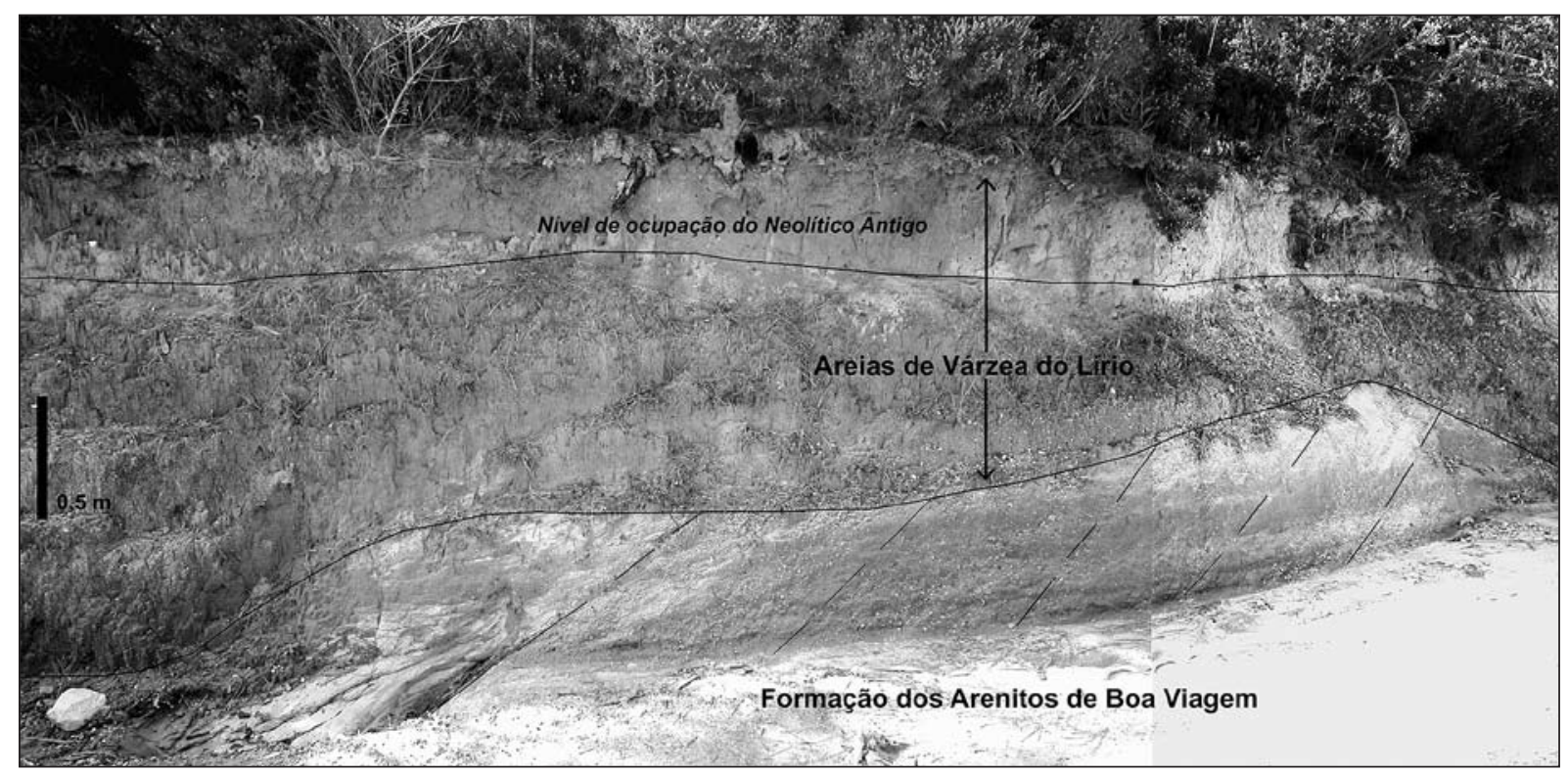

Fig. 3. Secção tipo da unidade Areias de Várzea do Lírio no caminho vicinal que da povoação do Lírio segue para Sul e atravessa o local de ocupação principal da Várzea do Lírio (denominado "Lírio II" no presente estudo e "L2" no mapa da figura 2).

Fig. 3. Type section of the Areias de Várzea do Lirio sandy unit exposed on the vicinal trail from Lírio to the South, crossing the main Neolithic site of Várzea do Lírio (named "Lírio II" on this work and "L2 in the map of figure 2).

Do ponto de vista litológico este último é constituído por areias finas a muito finas de tom amarelo claro, maturas, incoerentes. A análise granulométrica de 4 amostras recolhidas, a espaços regulares, entre a base e o topo do conjunto, revelou grande homogeneidade entre si. A composição mineralógica revela uma dominância de grãos de quartzo hialino a leitoso, subarredondados a subangulosos, de alta esfericidade, inseridos nas fracções de areia muito fina e fina, aos quais se juntam não raras palhetas de moscovite com dimensão de areia média a muito grosseira. As curvas granulométricas obtidas são bimodais, em virtude de também existir algum volume de pequenos grãos de quartzo com a dimensão de silte médio. Por fim, é comum a presença local de seixos de quartzo, quartzito e cherte negro, assim como de blocos de arenito, conglomerado ou calcário herdados do substrato jurássico ou, mais raramente, de algum depósito pré-existente a montante.

No mesmo perfil e porque o caminho vicinal atravessa a área da principal estação arqueológica local, observa-se que os cerca de $50 \mathrm{~cm}$ superiores contêm materiais líticos e cerâmicos in situ, demonstrando a relação evidente entre as áreas de ocupação pré-históricas e a disposição das Areias de Várzea do Lírio, assim como a grande mobilidade destes sedimentos holocénicos.

$\mathrm{Na}$ realidade, aquando de chuvadas mais intensas, é possível observar a formação superficial de materiais arenosos análogos, processada a partir da lavagem de sedimentos provenientes da erosão local de estratos de composição lutítica ou areno-lutítica da Formação dos Arenitos de Boa Viagem.

Não obstante, para a génese deste corpo arenoso deverá, também, ser admitida uma componente herdada de depósitos mais antigos, cujos materiais erodidos teriam sido transportados a partir de montante.

Desta forma, a deflação terá sido bastante importante na génese e acumulação das Areias de Várzea do Lírio em plataformas mais expostas aos ventos dominantes, sendo que o seu trânsito posterior através de depressões das vertentes contíguas acarretou, de igual modo, uma actuação continuada de processos hídricos, ligados a episódios de escorrência superfícial durante algumas precipitações mais intensas.

\section{Principais arqueossítios da baCia do RiO DE CARRITOS}

Com o levantamento cartográfico dos depósitos arenosos, foram identificados nove locais de ocupação principais (Fig. 2), com contextos que, no seu essencial, são representativos do Neolítico, incluindo o Neolítico Antigo de tipo cardial, mas que também contêm materiais de outras fases da Pré-História Recente e da Proto-História, incluindo o Calcolítico e a Idade do Ferro. Nalguns destes arqueossítios a extensão e densidade de materiais líticos e cerâmicos 
dispersos sugere ocupação persistente, relacionada com espaços aplanados e solos arenosos, favoráveis a práticas agro-pastoris rudimentares.

De igual modo, contabilizaram-se diversos outros locais com depósitos arenosos que revelaram fragmentos cerâmicos e líticos dispersos, incluindo núcleos e fragmentos de lâminas e lamelas em sílex e quartzo. Este facto reforça a ideia de uma presença humana continuada na região, parte importante do povoamento pré-histórico da região do Baixo Mondego.

As denominações seguintes respeitam, sempre que possível, os termos clássicos e a toponímia local. Tratando-se de uma primeira abordagem de estudos em curso, baseados em materiais a serem depositados nos acervos do Museu Municipal da Figueira da Foz, optou-se por uma descrição generalista sem maiores precisões cronológicas.

\subsection{Estações da Várzea do Lírio}

Lírio I - Comporta uma área aplanada de campos agrícolas e eucalipto, formando um degrau morfológico na vertente da serra, assente em calcários e margas do Jurássico Superior, cerca de 300m a Este do casario do Lírio. Esta área apresenta uma cobertura arenosa relativamente pouco espessa e, no seu limite oeste, um depósito coluvionar convergente para o Vale do Lírio. As coordenadas UTM do ponto médio são 29TNE1515048450. Terá sido este um dos sítios originais de recolha, ao tempo de Santos Rocha. Abundam sobretudo materiais líticos, incluindo lâminas e lamelas de silex, núcleos de vários tipos, etc. Não se encontraram fragmentos cerâmicos decorados, mas entre aqueles que constam no Museu Municipal da Figueira da Foz, existem exemplares com a designação de Várzea do Lírio que poderão ter vindo deste local. Recolheu-se ainda uma placa natural de xisto com estriações.

Lírio II - Terá sido este o principal local de recolha de Santos Rocha, no qual se procedeu, sob sua direcção, à abertura de sanjas no substrato arenoso. A área de ocupação situa-se ao longo da vertente suave que delimita o Vale do Lírio a oriente, cerca de 250 metros a sul das ruínas limítrofes da povoação. As coordenadas UTM do ponto médio são 29TNE1510048450. O depósito arenoso existente no local é visível em secção, ao longo do caminho vicinal. Assenta sobre arenitos e lutitos avermelhados do Jurássico Superior e sela diversos valeiros com exposições para o quadrante oeste, representativos da paleotopografia local do Plistocénico superior a Holocénico. A sua espessura ultrapassa, por vezes, os 3 metros, sendo que os materiais arqueológicos se encontram, sobretudo, nos $50 \mathrm{~cm}$ superficiais. Entre estes salienta-se uma debitagem numerosa em sílex e quartzo leitoso, bem como raras peças em quartzo hialino e anfibolito. Destacam-se diversas lâminas truncadas e lamelas de dorso rebaixado, com ou sem retoques, micrólitos, uma placa natural de xisto e um machado de xisto anfibólico, a par de fragmentos cerâmicos decorados, incluindo cardiais.

Por ser este local o de mais fácil acessibilidade, situado à saída da povoação, foi alvo de todo um conjunto de recolhas de superfície, mais ou menos exaustivas, ao longo de mais de um século. Não obstante, ainda deverá encerrar um espólio considerável, disperso pelas camadas superficiais da cobertura arenosa, a qual, apesar de remexida, deverá carecer de investigação mais detalhada.

Lírio III - Situa-se cerca de 300 m a ESE do sítio anterior, em área de cobertura arenosa disposta ao longo da vertente suave que delimita, a leste, o Vale do Lírio. As coordenadas UTM do ponto médio são 29TNE1530048050. Quanto a materiais de superfície, o local revelou bastantes fragmentos de cerâmica e debitagem em sílex, incluindo bordos com decoração plástica ou incisa afins aos de Lírio II. A presença de Calcolítico Final no extremo sul desta área de ocupação é, também, confirmada por um fragmento de taça campaniforme de tipo Palmela.

Lírio IV - Consiste num local de ocupação que julgamos inédito e que ocupa uma área de cobertura arenosa mais distante das anteriores. A espessura do depósito é fraca a vestigial na linha de cumeada, mas pode atingir alguns metros em locais onde ocorre convergência das areias móveis vertente abaixo, formando leques de escorrência orientados para leste e sudeste, em direcção ao Vale do Juncal. A área com materiais de superfície ocupa um espaço aplanado, sobranceiro à linha de cumeadas que separa os vales do Lírio e do Juncal, cerca de $1 \mathrm{~km} \mathrm{a}$ SSE das últimas habitações do Lírio. As coordenadas UTM do ponto médio são 29TNE1535047850. Observaram-se várias dezenas de peças à superfície, na sua maior parte fragmentos cerâmicos e de debitagem em sílex e em quartzo leitoso. Os materiais em pedra polida são ocasionais. Entre os muitos fragmentos cerâmicos presentes identificaram-se bordos com decoração cardial, plástica ou incisa, pegas mamilares e perfuradas e inúmeros fragmentos de bordo de diversa ordem, alguns deles carenados. Estes últimos sugerem possível presença de Neolítico Final.

Lírio V - Consiste num local de ocupação com substrato arenoso, mais remoto e situado cerca de 
$400 \mathrm{~m}$ a Sul do anterior, frente à vertente oriental do Vale do Lírio, um pouco a Norte da sua confluência com o Vale do Juncal. As coordenadas UTM do ponto médio são 29TNE1527547450. Este local forneceu, sobretudo, materiais cerâmicos, entre os quais raros bordos com decoração incisa.

\subsection{Estações da Asseiceira-Cubelo}

Cubelo Norte - Consiste numa área de ocupação desenvolvida sobre uma plataforma com cobertura arenosa, exposta a OSO e à cota média de $75 \mathrm{~m}$, encimando a vertente oriental do Vale do Juncal. Esta área faz parte da extensa linha de cumeada que, a partir do lugar de Asseiceira, se estende para sul, através do Cubelo e em direcção a Vale Raposo e a Caceira de Baixo. Observou-se bastante debitagem em sílex, incluindo muitas lâminas e lamelas, simples ou retocadas, em grande parte fragmentadas. As coordenadas UTM do ponto médio são 29TNE15575047500. O quartzo leitoso, embora menos abundante, também está presente, a par de três peças polidas em anfibolito. A cerâmica aparenta ser menos frequente do que nos locais de ocupação com tipologias afins ao Neolítico Antigo e consiste sempre em fragmentos não decorados e de menor espessura.

\subsection{Estações do Vale da Junqueira}

Junqueira I - Corresponde a um local de ocupação com características de povoado, situado no flanco oeste do Vale da Junqueira, numa área de cobertura arenosa disposta à cota de 90-100 m. As coordenadas UTM do ponto médio são 29TNE1635047850. Este sítio encontra-se, no presente, cerca de $150 \mathrm{~m}$ a oeste da auto-estrada A29, tendo sido poupado aquando dos trabalhos de construção. Não obstante, foi afectado por terraplanagem posterior, destinada a nivelar o fundo do vale, daí resultando ter sido coberto por aterro com materiais calcários e argilosos.

Terá sido este um dos principais locais amostrados ao tempo de Santos Rocha, situado no lado do vale oposto ao sítio do Prazo e cerca de $1 \mathrm{~km}$ a sul do dólmen das Carniçosas.

As areias locais revelaram muitos materiais cerâmicos de superfície, incluindo mais de uma dezena de fragmentos com motivos cardiais e incisos, bordos diversos, pegas mamilares e fragmentos muito espessos de vasos de provisões. Encontrou-se, igualmente, uma debitagem abundante em sílex e quartzo leitoso, em conjunto com lâminas e lamelas, geométricos, núcleos prismáticos, tabletes de núcleo, raspadores e ainda um elemento movente de mó e várias peças em anfibolito polido. A cobertura arenosa atinge localmente mais de 2 metros de es- pessura e deverá encerrar ainda grande quantidade de materiais in situ.

Junqueira II - Local de ocupação com características semelhantes ao anterior, situado cerca de $300 \mathrm{~m}$ a SSO e numa vertente suave virada a SSE, entre o Vale da Junqueira e a cumeada que o separa de Vale Romão. Localiza-se, também, numa área de cobertura arenosa espessa, à cota de 80-90 m, em que o depósito colmata um valeiro inciso em estratos areno-argilosos do Jurássico Superior. As coordenadas UTM do ponto médio são 29TNE1625047650. O local em questão forneceu também numerosos materiais cerâmicos, incluindo mais de duas dezenas de fragmentos com decoração cardial ou motivos incisos e plásticos, por vezes pertencentes à mesma peça. Os materiais líticos também são abundantes e com características similares aos do arqueossítio anterior. Destacam-se, entre outros, alguns micrólitos e um machado de anfibolito. À profusão de materiais dispersos à superfície, junta-se uma cobertura arenosa com interesse estratigráfico, ao selar a cerca de $50 \mathrm{~cm}$ da superfície, um nível com materiais frequentes, visível nos taludes de um caminho local.

Junqueira III - Consiste numa área de ocupação situada a SSW da anterior, no topo da vertente oriental com exposição para Vale Romão, à cota de $65-70 \mathrm{~m}$ e cerca de $300 \mathrm{~m}$ a Norte da confluência deste com o Vale da Junqueira. As coordenadas UTM do ponto médio são 29TNE1612547350. O local desta estação de superfície é uma área de pinhal com cobertura arenosa, que colmata um valeiro convergente para o fundo do vale. Os materiais revelados consistem, sobretudo, em debitagem em sílex, a par de alguma em quartzo e de fragmentos cerâmicos não decorados.

\subsection{Estações da plataforma arenosa das Arruelas}

Arruelas Norte - Os vestígios deste local de ocupação encontram-se em longas bolsadas arenosas que cobrem, ainda que parcialmente, a plataforma do lugar de Arruelas, situada a oriente do Vale da Junqueira, à cota de 90-95 m. As coordenadas UTM do ponto médio são 29TNE1665047500. Próximo do limite norte do coberto arenoso, em área florestal já parcialmente urbanizada por quintas, observaram-se muitos materiais talhados em sílex e em quartzo leitoso, incluindo lâminas, lamelas, micrólitos e núcleos de diversos tipos. Para além desta utensilagem identificaram-se materiais em pedra polida e várias dezenas de fragmentos cerâmicos, alguns dos quais bordos com decoração cardial e incisa. A 
debitagem sobre seixos de quartzo leitoso com córtex amarelado, provenientes de níveis conglomeráticos da Formação dos Arenitos de Boa Viagem, parece ser particularmente significativa.

Os materiais neolíticos de superfície ocorrem misturados com outros posteriores, comprovando a ocupação dos espaços arenosos durante diferentes fases, até à modernidade. Infelizmente, o extremo norte desta área foi terraplanado aquando da abertura dos caminhos de acesso ao lugar das Carniçosas e ao corredor N-S da auto-estrada A17.

\subsection{Outras referências}

Para além dos locais de ocupação anteriores, evidenciados por maior quantidade e diversidade de materiais arqueológicos, toda a vertente meridional da Serra da Boa Viagem, no troço drenado pela pequena bacia do Rio de Carritos, tem vindo a fornecer objectos dispersos, embora com maior incidência nas áreas com cobertura arenosa, as quais teriam tido, ao tempo, alguma ocupação.

Entre os diversos sítios que revelaram a presença de materiais neolíticos, destacam-se a Asseiceira, Vale Romão e Prazo, por já serem mencionados nos trabalhos monográficos de Santos Rocha. No primeiro destes locais observa-se um depósito coluvionar espesso com raros fragmentos cerâmicos e líticos in situ. Este está cortado, ao longo de uma centena de metros, pelo caminho vicinal que liga o Lírio às Carniçosas. Nesta secção era possível observar, ainda há alguns anos atrás, um alinhamento de blocos calcários que estaria ligado, muito possivelmente, a uma das mamoas descritas nas Memórias e Explorações Arqueológicas.

\section{Conclusões e Perspectivas futuras}

Os dados actuais sugerem que o povoamento do espaço envolvente ao braço norte do estuário do Mondego e às serras da Boa Viagem, das Alhadas e de Castros terá sido significativo durante o Neolítico. Para além dos muitos dólmens já reconhecidos sobre a cumeada do maciço calcário, são também numerosos os locais de ocupação existentes em seu torno, quer na área estudada, quer mais para Norte, entre as povoações de Quiaios, Brenha, Alhadas e Maiorca. Todos estes locais têm em comum a prevalência de solos arenosos e friáveis, a abundância em água e um certo resguardo relativamente a ventos dominantes.

No presente estudo e após se terem iniciado trabalhos de campo com vista a redescobrir estações humanas descritas por Santos Rocha, evidenciou-se a relação existente entre um conjunto expressivo de depósitos arenosos da vertente sul destas serras e o que terá sido uma das principais áreas de ocupação neolíticas da região, extensível a outras possíveis fases, mais tardias, da Pré-História Recente.

Este povoamento neolítico que teve lugar na proximidade e abrangência de ambientes litorais e estuarinos é, também, indissociável do óptimo climático do Holocénico Médio, durante o qual o upwelling costeiro terá sido, por várias vezes, bastante activo (SOARES 2010), com reflexos no clima regional e local.

$\mathrm{Na}$ realidade, por volta de $6 \mathrm{ka} \mathrm{BP}$, a tendência transgressiva de longo-termo, pós-glaciar, possibilitou que o nível do mar atingisse valores próximos dos actuais (DIAS et al. 1997, 2000), antecedendo o início da construção de estruturas barreira e de lagunas ao longo da orla litoral circundante ao Cabo Mondego (BERNARDES et al. 2001; CASTILHO 2008; DANIELSEN et al. 2008, 2011; DANIELSEN 2010). Neste quadro, o vale estuarino do Rio Mondego apresentaria um enchimento sedimentar bastante menos volumoso do que o actual, permitindo uma dispersão significativa de areias marinhas com abundantes faunas de moluscos comestíveis e de outros invertebrados de meio euhalino e salobro.

Para o curso inferior do Rio de Carritos, sobranceiro aos vales do Lírio e da Junqueira e hoje colmatado por inteiro com sedimentos aluviais tardi-holocénicos, esta acepção da evolução paleogeográfica local/regional coaduna-se com a existência de um pequeno braço de estuário, algo confinado, mas ainda assim integrando vários ecotonos, com a consequente diversidade biológica e abundância em recursos alimentares.

Em torno deste espaço singular é plausível que mais locais de ocupação possam ser encontrados, apesar da pressão antrópica crescente a que a bacia de drenagem do Rio de Carritos está sujeita. Assim sendo e face ao risco de destruição latente de alguns arqueossítios, julgamos importante a sua pronta inventariação, ordenamento e protecção através de uma carta arqueológica, ainda inexistente à data, assim como através de uma maior informação e sensibilização do Município da Figueira da Foz.

\section{Agradecimentos}

O nosso reconhecimento mais expressivo vai para os Doutores António Campar de Almeida, Ana M. S. Bettencourt e José Brandão, pela leitura crítica, ensinamentos e sugestões preciosas para o aperfeiçoamento do presente trabalho. 


\section{BIBLIOGRAFIA}

AlmeIDA, A.C. 1992. Os depósitos superiores da Serra da Boa Viagem e seu significado. Cadernos de Geografia 9: 151-162.

AlmeIDA, A.C. 1995. Dunas de Quiaios, Gândara e Serra da Boa Viagem. Uma abordagem ecológica da paisagem. Coimbra: Faculdade de Letras da Universidade de Coimbra. Tese de Doutoramento.

AlmeidA, A.C. 2006. Morfologia da Serra da Boa Viagem e das Dunas de Quiaios. In F.C. Lopes \& P.M. Callapez (eds.) As Ciências da Terra ao Serviço do Ensino e do Desenvolvimento: O exemplo da Figueira da Foz. Figueira da Foz: Kiwanis Clube da Figueira da Foz: 85-94.

AlmeidA, A.C.; SoAres A.F.; CunHA, L. \& MArQues, J.F. 1990. Proémio ao estudo do Baixo Mondego. Biblos 66: 17-47.

Barbosa, B.P.; SoAres, A.F.; Rocha, R.B.; Manuppella, G. \& HenriQues, M.H. 1988. Carta Geológica de Portugal. Noticia Explicativa da Folha $n .^{\circ} 19-A-C a n t a n h$ de. Lisboa: Serviços Geológicos de Portugal.

Bernardes, C.M.; Noivo, L.M. \& Corrochano, A. 2001. Evolution of Holocenic Coastal Dunes at Leirosa, South of Cape Mondego, Portugal. Thalassas 17 (2): 47-56.

Cabral, J. 1995. Neotectónica em Portugal Continental. Memórias do Instituto Geológico e Mineiro 31: 1-265.

Callapez, P.M. 2008. Subsídios para um roteiro geoturístico do litoral Português: o exemplo da Figueira da Foz. In F.C. Lopes \& P.M. Callapez (eds.) Por terras da Figueira. Figueira da Foz: Kiwanis Clube da Figueira da Foz: 115-129.

Callapez, P.M. \& PINTO, J.S. 2005. Tesouros geológicos e naturais da Região da Figueira da Foz: perspectivas de intervenção no Ensino Básico e Secundário. Litorais, Revista de Estudos Figueirenses 3: 57-81.

CAllapez, P.M. \& PINTO, J.S. 2010. Uma laguna tropical no Jurássico Superior do Cabo Mondego. Litorais, Revista de Estudos Figueirenses 11: 95-116.

Carvalho, A.F. 2008. O Neolítico Antigo do Baixo Mondego. In R. Vilaça \& J.P. Cunha-Ribeiro (eds.) Das primeiras ocupações humanas à chegada dos Romanos à Beira Litoral. Tomar: CEIPHAR. Arkeos 4: 32-35.

CArvalho, G.S. 1964. Areias da Gândara (Portugal). Uma formação eólica quaternária. Anais da Faculdade de Ciências do Porto 81: 1-32.

Castilho, A.M. 2008. Lagoas de Quiaios. Contribuição para o seu conhecimento geológico e hidrogeológico. Coimbra: Universidade de Coimbra. Tese de Doutoramento.

CunHA, L. 1990. As serras calcárias de Condeixa - Sicó - Alvaiázere. Estudo de Geomorfologia. Colecção Geografia Física, n. ${ }^{\circ} 1$. Coimbra.

DANIELSEN, R. 2010. Late Holocene environmental change at the Quiaios-Tocha coastal plain. Braga: Universidade do Minho. Tese de Doutoramento.

Danielsen, R.; Castilho, A.; Callapez, P.M. \& Dinis, P.M. 2008. Evolução da paisagem a norte do Cabo Mondego durante os últimos milhares de anos. In F.C. Lopes \& P.M. Callapez (eds.) Por terras da Figueira. Figueira da Foz: Kiwanis Clube da Figueira da Foz: 45-53.

Danielsen, R.; Castilho, A.M.; Dinis, P.; CAmpar, A.; CallaPEZ, P.M. 2011. Holocene interplay between a dune field and coastal lakes in the Quiaios - Tocha region, central littoral Portugal. Holocene (accepted).

Dias, J.M.A.; Boski, T.; Rodrigues, A. \& Magalhães, F. 2000. Coast line evolution in Portugal since the Last Glacial Maximum until present - a synthesis. Marine Geology 170: 177-186.
Dias, J.M.A.; Rodrigues, A. \& Magalhães, F. 1997. Evolução da linha de costa, em Portugal, desde o Último Máximo Glaciário até à actualidade: Síntese dos conhecimentos. Estudos do Quaternário 1: 53-66.

Dinis, J.L. 2001. Definição da Formação da Figueira da Foz Aptiano a Cenomaniano do sector central da margem oeste ibérica. Comunicações do Instituto Geológico e Mineiro 88: 127-160.

FERrEIRA, A.M. 1999. Santos Rocha e a Sociedade Arqueológica. In A.M. Ferreira \& A.P. Cardoso (eds.) Sociedade Arqueológica da Figueira. Centenário. Figueira da Foz: Museu Municipal Dr. Santos Rocha: 13-17.

Figueiredo, A. 1943. A Pré-História do concelho de Figueira - Foz do Mondego. Trabalhos de Antropologia e Etnologia, Revista da Sociedade Portuguesa de Antropologia e Etnologia 10: $57-63$.

Guerra, V. 1969. António dos Santos Rocha - Notícias Arqueológicas. O Arqueólogo Português, 3, Série III: 261-284.

GuerrA, V. \& FerreirA, O.V. 1968-1970. Inventariação dos monumentos megalíticos dos arredores da Figueira da Foz. Arquivo de Beja 25: 45-56.

Guerra, V. \& Ferreira, O.V. 1972. A importância da estação neolítica de Santa Olaia para o estudo do Neolítico em Portugal. Arqueologia e História, 9, Série IV: 49-64.

Guerra, V. \& FerreirA, O.V. 1979. A importante colecção de instrumentos de fibrolite do Museu Dr. Santos Rocha na Figueira da Foz. Revista de Guimarães 89: 321-326.

Guilaine, J. \& Ferreira, O.V. 1970. Le Néolithique ancien au Portugal. Bulletin de la Société Préhistorique Française 67: 308-312.

JORGE, S.O. 1979. Contributo para o estudo de materiais provenientes de estações neolíticas dos arredores da Figueira da Foz. Actas da 1. ${ }^{a}$ Mesa Redonda sobre o Neolítico e Calcolítico em Portugal 1: 53-82.

PEREIRA, M.I.S. 1975. Os imóveis classificados do concelho da Figueira da Foz. Cadernos Municipais. Câmara Municipal da Figueira da Foz 11: 48-50.

PereIRA, M.I.S. 1985. Museu Municipal: Notícia Histórica. Cadernos Municipais da Câmara Municipal da Figueira da Foz.

PereirA, M.I.S. 1999. Santos Rocha, o Museu Municipal, a Sociedade Arqueológica e o Boletim. In A.M. Ferreira \& A.P. Cardoso (eds.) Sociedade Arqueológica da Figueira. Centenário. Figueira da Foz: Museu Municipal Dr. Santos Rocha: 49-51.

Perpétuo, J. \& CARvalho, P.S. 2006. O Dólmen 2 das Carniçosas, Alhadas, Figueira da Foz. Escavação, restauro e valorização. In N. Bicho (ed.) Simbolismo, Arte e Espaços Sagrados. Actas do IV Congresso de Arqueologia Peninsular, Faro, 14 a 19 de Setembro de 2004. Faro: Centro de Estudos de Património do Departamento de História, Arqueologia e Património da Universidade do Algarve. Promontoria Monográfica 5: 111-122.

Pinto, J.S. \& CAllapez, P.M. 2006. O património mineiro do Cabo Mondego. Litorais, Revista de estudos figueirenses 4: 67-80.

Ramos, A.; CunHA, P.C. \& Gomes, A. 2009. Os traços geomorfológicos da área envolvente da Figueira da Foz e a evolução da paisagem durante o Pliocénico e Plistocénico. Publicações da Associação Portuguesa de Geomorfólogos 6: 9-16.

RochA, A.S. 1905. O Museu Municipal da Figueira da Foz: Catálogo Geral, com indicação dos escriptos e desenhos que se têem publicado sobre muitos dos objectos catalogados. Figueira da Foz: Imprensa Lusitana.

RochA, A.S. 1949. Memórias e Explorações Arqueológicas. Vol. 
I - Antiguidades Pré-históricas do Concelho da Figueira da Foz. 2. ${ }^{a}$ Edição. Coimbra: Acta Universitatis Conimbrigensis.

Rocha, A.S. 1971. Memórias e Explorações Arqueológicas. Vol. II - Estações Pré-Romanas da Idade do Ferro nas visinhanças

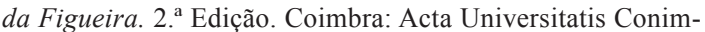
brigensis.

Rocha, A.S. 1975. Memórias e Explorações Arqueológicas. Vol. III - Memórias sobre a Antiguidade. 2. ${ }^{a}$ Edição. Coimbra: Acta Universitatis Conimbrigensis.

RochA, A.S. 1954. Materiais para a história da Figueira nos Séculos XVII e XVIII. 2. ' edição. Figueira da Foz: Câmara e Museu Municipal.

Rocha, R.B.; Manupella, G.; Mouterde, R.; Ruget, C. \& ZBYSZewsKi, G. 1981. Carta Geológica de Portugal na escala de 1:50.000. Notícia explicativa da folha 19-C Figueira da Foz. Lisboa: Serviços Geológicos de Portugal.

SOARES, A.F. 2000. As unidades pliocénicas e quaternárias no espaço do Baixo Mondego (uma perspectiva de ordem). Estudos do Quaternário 2: 7-17.

Soares, A.F.; Callapez, P.M. \& Marques, J.F. 2007. The Farol Deposit (Depósito do Farol). A Pleistocene beach deposit from Cape Mondego (Figueira da Foz, West Central Portugal). Ciências da Terra 16: 163-173.

SoAres, A.F.; Cunha, L. \& MArques, J.F. 1992. Depósitos qua- ternários do Baixo Mondego. Tentativa de correlação morfogenética. Actas da III Reunião do Quaternário Ibérico 1: 803-812.

Soares, A.F.; Cunha, L. \& Marques, J.F. 1992. Depósitos quaternários do Baixo Mondego. Estado actual dos conhecimentos e tentativa de coordenação morfogenética. Actas do VI Colóquio Ibérico de Geografia 1: 773-782.

SoARes, A.F.; Cunha, L.; MARQues, J.F.; AlmeidA, A.C. \& LAPA, M.R. 1993. Depósitos de vertente no Cabo Mondego. Integração no modelo evolutivo do Quaternário do Baixo Mondego. Actas da III Reunião do Quaternário Ibérico 1: 199-208.

SOARES, A.M.M. 2010. Upwelling, efeito de reservatório, radiocarbono: construção de cronologias absolutas e inferências paleoambientais. In A.M.S. Bettencourt, M.I.C. Alves \& S. Monteiro Rodrigues (eds.) Variações Paleoambientais e Evolução Antrópica no Quaternário do Ocidentente Peninsular $/$ I Paleoenvironmental Changes and Anthropisation in the Quaternary of Western Iberia. Braga: Associação Portuguesa para o Estudo do Quaternário - APEQ e Centro de Investigação Transdisciplinar. Cultura, Espaço e Memória (Paisagens, Fronteiras e Poderes), CITCEM: 11-22.

VILAÇA, R. 1988. Subsídios para o estudo da Pré-História Recente do Baixo Mondego. Trabalhos de Arqueologia 5: 1-114.

VilhenA, H. 1937. O Dr. António dos Santos Rocha (elogio, notas, bibliografia de $S$. R., notas de bibliografia sobre $S$. R.). Lisboa: Edição do Autor. 